\title{
PIK3CA NM_006218.1:C.1633G>C
}

National Cancer Institute

\section{Source}

National Cancer Institute. PIK3CA NM 006218.1:C.1633G>C. NCI Thesaurus. Code C98471.

A nucleotide substitution at position 1633 of the coding sequence of the PIK3CA gene where guanine has been mutated to cytosine. 